\title{
EDUCAR E CUIDAR: UMA POSSIBILIDADE DE AÇÃO ENTRE FINANÇAS E MEIO AMBIENTE
}

\section{EDUCATE AND CARE: AN ACTION BETWEEN THE POSSIBILITY OF FINANCE AND ENVIRONMENT}

\author{
Luciana Troca Dantas ${ }^{1}$, Barbara Cristina Mathias dos Santos ${ }^{2}$, Giseli Capaci Rodrigues ${ }^{3}$, \\ Chang Kuo Rodrigues ${ }^{4}$ \\ ${ }^{1}$ UNIGRANRIO, PPGEC-Programa de Pós-Graduação no Ensino das Ciências, lucianatroca@ig.com.br \\ ${ }^{2}$ UNIGRANRIO, PPGEC-Programa de Pós-Graduação no Ensino das Ciências, barbara- \\ cms@hotmail.com \\ ${ }^{3}$ UNIGRANRIO PPGEC-Programa de Pós-Graduação no Ensino das Ciências, giselicapaci@ gmail.com \\ ${ }^{4}$ UNIGRANRIO, PPGEC-Programa de Pós-Graduação no Ensino das Ciências, \\ changkuockr@gmail.com
}

\begin{abstract}
RESUMO
Este trabalho, realizado pelo Grupo de Pesquisa e Investigação no Ensino de Matemática e Ciências, na base do CNPq e validado pela Universidade do Grande Rio, apresenta questões pertinentes a estratégias de ensino de educação financeira nos anos iniciais do Ensino Fundamental. Esta investigação defende o entrelaçar entre dois temas: meio ambiente e situações financeiras. Consequentemente, há possibilidade de inserir elementos didáticos para a formação cidadã a partir do trabalho na dimensão atitudinal, tal como é preconizada nos documentos oficiais, desde os anos iniciais, de forma a promover uma sociedade mais dinâmica e responsável, com indivíduos preparados e conscientes de seu papel no cuidado com o futuro. Um dos objetivos deste estudo incide em analisar questões pertinentes ao tema, como o consumismo compulsivo, endividamento, cuidados com o planeta, entre outros. Diante disso, apresentamos uma sequência de ensino para a construção de conceitos de educação financeira e consumo consciente, nos anos iniciais do Ensino Fundamental. A metodologia de pesquisa repousa sob os pressupostos da Engenharia Didática, quando as observações diretas representam a leitura das pesquisadoras sobre a situação e sua descrição fundamentada à luz da Teoria das Situações Didáticas.
\end{abstract}

Palavras-chave: Ensino. Educação Matemática. Finanças. Teoria das situações didáticas. Sustentabilidade.

\begin{abstract}
This work conducted by the Research Group which name is Research in Mathematics and Science Teaching, based on $\mathrm{CNPq}$ and validated by the Universidade do Grande Rio, presents issues relevant to financial education teaching strategies in the Elementary School. This research supports the intertwining between two themes: the environment and financial situations. Consequently there is the possibility of entering training aids for civic education from the work on attitudinal dimension, as recommended in the official documents from the early years, in order to promote a more dynamic and responsible society, with individuals prepared and aware of their role in caring for the future. One of the objectives of this study focuses on analyzing issues related to the theme, such as compulsive consumerism, debt caring for the planet and others.
\end{abstract}


Therefore, we present a teaching sequence for building financial education concepts and the conscious consumption in the elementary school. The research methodology is support by Didactic Engineering when direct observations represent the reading of the researchers on the situation and description based on the Theory of Didactic Situations.

Keywords: Basic Teaching. Mathematics Education. Finance. Theory of didactic situations. Sustainability.

\section{INTRODUÇÃO}

Educação financeira é um processo que se desenvolve ao longo da vida e pressupõe a preparação das pessoas para que sejam consumidores responsáveis, informados e exigentes, com a promoção permanente de seu desenvolvimento pessoal e profissional, ensejando o reforço à cidadania e ao desenvolvimento de valores, resultando em uma sociedade civil mais ativa e dinâmica.

Nesse sentido, Niskier (2012) diz que a promoção de um modelo de desenvolvimento sustentável deve, invariavelmente, investir na educação e, por isso, os currículos trabalhados nas escolas deveriam priorizar projetos interdisciplinares, com temas pertinentes à realidade dos alunos, incluindo as questões ambientais. Ele defende o estímulo à conscientização ecológica, de forma a preparar os jovens para o desenvolvimento econômico e tecnológico, de forma sustentável.

A proposta deste artigo visa mostrar alguns resultados a respeito de sequências didáticas que relacionam a educação financeira e o consumo consciente, no sentido de estimular a dimensão atitudinal das crianças do $4^{\circ}$ ano do Ensino Fundamental. Para tal, apresentaremos uma sequência didática que proporcionou reflexão dos alunos sobre a conscientização da educação financeira e, posteriormente, ocasionou um breve comentário sobre os resultados coletados.

A metodologia de pesquisa é a Engenharia Didática e a descrição está fundamentada à luz da Teoria das Situações Didáticas de Brousseau (2008), que analisa as interações entre alunos, professores e conhecimentos matemáticos e leva a uma reflexão sobre a necessidade de dar sentido aos conhecimentos transmitidos aos alunos. O foco deste trabalho é conduzido pelas questões relacionadas a situações financeiras e o meio ambiente. 


\section{EDUCAÇÃO FINANCEIRA E CONSUMO COMPULSIVO}

Atualmente, no Brasil, observamos uma grande parcela da população consumidora compulsiva. A proposta de educação financeira nas escolas vem ao encontro à essa realidade, ensejando consumidores mais disciplinados, ponderados e que saibam lidar com o dinheiro e com a intenção de deixar um legado mais promissor, em termos ecológicos, para as futuras gerações; estimulando as crianças e os jovens a evitarem o consumismo exagerado e o desperdício, almejando adultos comprometidos e responsáveis com as questões ambientais.

Kiyosaki (2000) alerta que um dos grandes problemas do endividamento está no fato dos indivíduos serem, em grande parte, "analfabetos financeiros", ou seja, não tiveram ou tiveram pouca instrução financeira, o que acaba comprometendo seus objetivos e seu futuro. Diante disso, infere-se que os jovens terão grandes responsabilidades com o planeta e com o seu futuro. Deverão se preparar para absorver demandas atualmente administradas pelo Estado, como Saúde, Educação, Aposentadoria e sustentabilidade do planeta. De acordo com Ferreira (2013), o grau de exigência e de responsabilidade dos mais novos será ainda maior daqui para frente; os cidadãos vão ter que ser mais responsáveis de forma individual e em temáticas que até aqui delegavam ao Estado, como saúde e previdência.

Conforme Campos (2012) aponta, a economia mundial tem atravessado profundas transformações. Em suas palavras:

\footnotetext{
Nosso país, em particular, em menos de vinte anos, saiu de uma situação de hiperinflação, passando por um período de ampliação de consumo e de acesso ao crédito acompanhado de um preocupante nível de endividamento e desemprego da população. O sistema de ensino brasileiro não tem acompanhado tais transformações no que diz respeito a uma proposta de Educação Financeira para seu público alvo. (CAMPOS, 2012, p.30).
}

Niskier (2012) alerta sobre a importância de preparar os jovens, financeiramente e ecologicamente, envolvendo-os em questões financeiras, incentivando-os a reciclar, doar, proteger o meio ambiente. Princípios éticos, financeiros, de cidadania e sustentabilidade, devem fazer parte do cotidiano escolar e familiar, para que esses jovens cresçam com responsabilidade e conscientes das consequências positivas ou mesmo, negativas de suas escolhas. É importante preparar as crianças para quando forem adultos, já que terão grandes desafios relacionados à escolha de consumo. Diante disso, os pais (e/ou responsáveis) e os professores deverão encontrar estratégias que ajudem as crianças a "hierarquizar opções de consumo, e que 
sejam capazes de fazer análises racionais em detrimento de impulsos" (FERREIRA, 2013, p. 120). A decisão de poupar ou de consumir é complexa, sendo influenciada também por fatores sociais, psicológicos e culturais. "Consumir virou o verdadeiro propósito da existência humana, o desejo, a vontade e os anseios são condições essenciais para que o consumo seja reconhecido na atualidade; foi necessário entender a incorporação da Educação Financeira na escola como uma necessidade do mundo". (VARGAS, 2012, p.21).

Desenvolvimento sustentável é um termo empregado no sentido de melhorar a qualidade de vida, dentro dos limites suportáveis pelos ecossistemas (ROMEIRO, 2012). Esse processo exige disciplina, fiscalização e ações concretas, refletindo no trabalho dos professores, que "plantam a sementinha" em cada turma, de cada região do mundo, com cada um fazendo a sua parte, tendo o objetivo comum de deixar um mundo melhor para nossos filhos, netos, enfim, para as gerações futuras. Dentro do contexto da matemática, podem ser exploradas questões ambientais, como poluição, desmatamento, lixo, recursos naturais etc., contribuindo para a formação do aluno, com vistas à conquista do exercício da cidadania. Cabe aos professores encontrar mecanismos de melhor trabalhar tais questões, levando ao desenvolvimento do senso crítico dos alunos.

A ausência da educação financeira nos documentos oficiais que dizem respeito ao currículo do Ensino Fundamental, Parâmetros Curriculares Nacionais (PCN) e nas Diretrizes Curriculares Nacionais, por exemplo, pode ser um fator importante que justifica a pertinência das pesquisas que estão em voga sobre este tema tão importante na formação do cidadão. Estar educado financeiramente pode contribuir para a formação de atitudes que potencializam o consumo sustentável; é importante definir prioridades, ou seja, planejar; pequenos gestos podem fazer diferença no futuro.

Aprender a controlar a ansiedade no momento de adquirir um determinado bem é tarefa difícil, face ao progressivo poder do marketing e, por isso, aprender a limitar as opções disponíveis é uma estratégia eficaz. Um exemplo simples é, ao invés de perguntar o que a criança quer de presente, opta-se por colocar a questão de uma forma mais direta: jogo ou boneca? Com pequenas estratégias de negociação, a criança vai desenvolvendo uma maior capacidade de tolerância e controle da ansiedade. Ferreira (2013) adverte que a chantagem emocional ou pirraça, a qual muitas crianças recorrem, é uma forma de testar os limites das regras que foram impostas. Pais e filhos devem aprender a negociar, mas sem desrespeitar os acordos realizados, "os pais precisam ser coerentes nos seus discursos", como bem defende Ferreira (2013). É um caminho 
progressivo de aprendizagem, tanto para as crianças, como para os pais. Para haver aprendizagem, a persistência por parte do professor é imprescindível, pois vale destacar que aprender a consumir é tarefa difícil e árdua, visto que os desafios são muitos, ainda mais se levarmos em consideração que as crianças vivem na era digital, quando todas as informações e opções de consumo podem caber na palma da mão.

É importante ressaltar que as crianças levam para a vida os ensinamentos adquiridos em casa, então, se crescem em um meio com tendência ao consumo compulsivo e endividamento, sofrerão essas influências. A educação financeira é fundamental para sua formação pessoal, permitindo-lhes adaptar atitudes no futuro. Os pais e/ou responsáveis deveriam fazer esforço em servir de exemplo em decisões de questões financeiras, além de dedicar tempo aos filhos, realizar atividades diversas, como lazer, educação e formação. Os valores transmitidos aos jovens, pela família e pela escola, são fundamentais, devendo promover a integridade, solidariedade e respeito ao próximo.

Há que se ter cuidado com o fato de alguns pais, achando que estão educando financeiramente seus filhos, atribuírem mesadas ou presentes como alternativas a uma postura educacional responsável e comprometida com valores éticos. Educação não pode ser premiada materialmente, é obrigação para e do aluno. Uma boa educação não retira as pedras do caminho, ela ensina a removê-las, parafraseando sábios pensamentos.

Segundo a psiquiatra Dra. Ana Beatriz B. Silva (2014, p.9), em seu livro Mentes Consumistas, "crianças poupadas em excesso se tornam adultos que veem problemas com maior gravidade do que de fato eles têm". Resultado: reações de estresse frente às adversidades podem se tornar fator desencadeante que leva a compras abusivas e descontrole financeiro. Tais ações de comprar compulsivamente são alimentadas e exaltadas em nossa cultura consumista, quando os indivíduos são valorizados pelo que têm, e não pelo que são.

Por que compramos? A resposta a essa pergunta simples é de fato complexa: por necessidade, por prazer, por lazer, passatempo, extravagância, capricho, materialismo, status. De forma sucinta, pode-se dizer que "tudo" se resume a recompensa. Como controlar tais impulsos? Ensinando nosso cérebro a tomar decisões mais satisfatórias.

Kistemann e Lins (2014) buscaram investigar as tomadas de decisão de indivíduos referentes ao consumo, pesquisando formas de contribuir para educar pelo consumo, ou seja, contribuir nas discussões junto aos professores que ensinam 
matemática e das demais áreas de ensino, para a tomada de decisão em situações financeiras, possibilitando caminhos e reflexões. Estendendo o caminho das possibilidades de ação, Silva (2014) define o que vem a ser um consumidor consciente:

Ser um consumidor consciente é o mesmo que ser um cidadão melhor, mudando sua maneira de encarar os desafios atuais relacionados às nossas fontes de água potável e de energia, ao lixo produzido, às embalagens plásticas que destroem a natureza, à reciclagem, à redução dos níveis de gás carbônico na atmosfera, etc. (SILVA, 2014, p.36).

$\mathrm{Na}$ prática, deve-se ensinar os jovens a evitar o desperdício e o consumismo exagerado, além de preparação para questões de sustentabilidade do planeta. Na escola, é importante orientar a criança quanto ao consumo da merenda oferecida e, nos casos de não haver merenda, deverá ser incentivado o lanche preparado em casa, por ser mais saudável, evitando frituras, refrigerantes e excesso de açúcar em doces. Alguns pontos importantes devem ser trabalhados desde cedo, como conversar em casa e na escola sobre os objetivos e os riscos da publicidade para o público infantil. A criança deverá, desde cedo, aprender a fazer escolhas, dentro das possibilidades dos pais. Nas compras, é necessário o estabelecimento de regras, ainda em casa, para evitar conflitos e constrangimentos em público. É importante definir previamente o objetivo das compras, sendo comprometedor associar o ato de consumir com o prazer de passear. No caso de comprar algo, o comportamento do adulto como consumidor será de negociar e comparar preços, sendo importante estimular a negociação e o rigor, como etapas (desgastantes) do ato de consumir, devendo ser ensinadas em casa e na escola.

Kiyosaki (2000) alerta para o fato das pessoas aprenderem a dominar o dinheiro, no sentido de saber lidar, evitando gastos desnecessários. A questão é: como conquistar a tão sonhada inteligência financeira, em um mundo que dá mais ênfase à despesa do que à poupança? Alia-se a este fato, a ausência da educação financeira nas escolas.

No Brasil, está ocorrendo uma proliferação de indivíduos consumidores compulsivos. A cultura consumista e individualista está tão profundamente enraizada em nosso comportamento diário que, na maioria das vezes, não percebemos o quanto vivemos sob a ditadura do ter e, nesse sentido, salienta Silva (2014). Segundo a mesma autora,

[...] a partir do século XVIII, estabelecemos um sistema econômico que passou a priorizar a produção e o lucro em detrimento da ética e dos valores humanos; consumir passou a ser a maneira mais rápida e eficaz de ter, com isso, as pessoas passam a comprar cada vez mais, na tentativa de ter prazer, 
viram consumidoras compulsivas e perdem o controle financeiro, resultando em endividamentos. (SILVA, 2014, p.20)

O Instituto de Defesa do Consumidor (IDEC), uma associação sem fins lucrativos, busca promover a conscientização e defesa dos consumidores, debatendo a relação entre consumo e sustentabilidade. Segundo o órgão, "ou se alteram os padrões de consumo ou não haverá recursos naturais nem de qualquer outro tipo para garantir o direito das pessoas a uma vida sustentável, bem como não haverá como garantir o direito de acesso universal sequer aos bens comuns" (IDEC, 2005 apud ARAÚJO, 2009, p. 75).

Crianças que são bem orientadas e estimuladas a desenvolver consciência financeira, no futuro, irão se tornar adultos mais responsáveis e preocupados com o meio ambiente, evitando o consumismo, planejando seus gastos, sabendo lidar com o dinheiro, indispondo-se ao que é fútil, ficando longe de atividades que possam comprometer seus objetivos e seu futuro.

A necessidade de definir prioridades de consumo, denominado por Ferreira (2013) de custo de oportunidade em Economia, o qual é um conceito abstrato e técnico para as crianças, mas necessário e relevante. $\mathrm{O}$ mesmo autor ainda defende que tanto os pais como os professores, devem encontrar estratégias para preparar as crianças para as escolhas que se farão necessárias ao longo da vida, mostrando opções de consumo com responsabilidade, evitando os impulsos de consumo irrefletidos. Propõe trabalhar com as crianças a tolerância aos ímpetos consumistas, sabendo lidar com o progressivo poder do marketing (FERREIRA 2013).

Tal preparação é um caminho contínuo de aprendizagem, com desenvolvimento das capacidades de negociação, tolerância e controle da ansiedade, fundamentais para tornarem-se consumidores responsáveis. De início, podem existir situações complexas, em que haverá necessidade do adulto responsável ajudar a resolver o dilema, colocando questões que possam desbloquear a paralisação na definição de prioridades, sendo importante a criança acompanhar a resolução do problema para, no futuro, ser capaz de resolver sozinha. Ainda nos argumentos de Ferreira (2013), os pais ou os professores devem provocar a curiosidade das crianças na resolução de um problema que envolva consumo; a partir da definição e análise das diferentes soluções sugeridas; estabelecer um plano de ação e de controle do processo de forma a garantir a resolução do problema, além de observação prática da mesma. Saber tomar decisões 
inteligentes frente a diferentes opções de consumo é tarefa difícil, requer estratégias e certa dose de experiência.

Com a melhoria da renda da população no Brasil, que gerou uma ascensão econômica, surgiram novos consumidores, que passaram a ter contato com instrumentos e operações financeiras, sem que estivessem preparados para compreendê-los e lidar com eles, tais como: créditos, poupanças, corretoras, serviços on-line, seguros, previdência privada etc. Tal despreparo, ocasionado pela falta de uma educação financeira, levou muitas pessoas ao endividamento. Vargas (2012), que defende a educação financeira como disciplina obrigatória nas escolas, diz que "devemos preparar o educando para lidar com assuntos relacionados à realidade, além de torná-los consumidores responsáveis, pois só assim a escola possibilitaria aos alunos se educar financeiramente, consumir conscientemente e se tornar empreendedores". (VARGAS, 2012, p.22).

Os alunos também devem ser alertados para os riscos do endividamento com o cartão de crédito, sendo este um recurso financeiro perigoso e sedutor, traduzindo-se em crédito pessoal imediato e automático, definido em função da capacidade financeira do portador do cartão, quando são cobrados juros, em caso de parcelamento ou não pagamento, que podem levar à inadimplência. Deve-se enfatizar que o uso do cartão de crédito traduz-se em ausência de dinheiro na carteira ou no banco, dinheiro esse fruto do trabalho laboral dos pais e/ou responsáveis. O dinheiro para pagar a fatura do cartão deverá ser ganho nos meses precedentes, não esquecendo que nesses meses também ocorrerão despesas, que serão somadas às já adquiridas nos meses anteriores. O ideal é restringir seu uso a situações de emergência e não pontuais.

\section{ABORDANDO EDUCAÇÃO FINANCEIRA E CUIDADOS COM O AMBIENTE NAS AULAS DO ENSINO FUNDAMENTAL}

Um desafio interessante visa conciliar os programas curriculares com as temáticas envolvendo educação financeira e meio ambiente. Uma forma de abordagem poderá ser por meio de exemplos concretos, nesse caso, nas aulas de matemática, com recursos às finanças pessoais. Vale destacar que os livros didáticos utilizados em salas de aulas carecem de exemplos assim e, consequentemente, a introdução de programas de educação financeira e meio ambiente nas escolas, não pode se dar em casos isolados. 
O trabalho tem como fundamento a Teoria das Situações Didáticas de Brousseau (2008), que analisa as interações entre professor, alunos e saberes matemáticos, procurando dar sentido aos conhecimentos transmitidos aos alunos e têm como objeto de estudo, as condições nas quais os alunos interagem com a matemática. Partindo das ideias de Brousseau em que o professor deverá apresentar progressivamente as ideias aos alunos e da proposta do presente trabalho, qual seja, buscar estratégias para incentivar os alunos a terem um consumo mais consciente e sustentável, pretende-se, com as tarefas, alcançar os objetivos propostos. Espera-se do aluno, nessa perspectiva, a utilização dos conhecimentos no seu cotidiano e compreender efetivamente e satisfatoriamente os conceitos trabalhados nas situações futuras, questionando e tomando decisões apropriadas, levando esses conceitos para sua vida e tornando-se agente multiplicador.

A mudança do aluno é uma ação intencional do professor, legitimada conforme alguns fatores: o saber comunicado não é arbitrário, corresponde a um saber em curso de uma instituição de referência; tal saber modifica o aluno e revela sua eficiência quando utilizado a posteriori; a ação termina quando o aluno é capaz de tomar decisões satisfatórias por si mesmo (BROUSSEAU, 2008).

Nesta pesquisa, a partir da proposta de Artigue (1987), as observações diretas representam a leitura das pesquisadoras sobre a situação, de modo que sua descrição é fundamentada à luz da Teoria das Situações Didáticas de Brousseau, portanto, envolvendo diretamente um triângulo didático compreendido entre os alunos, o saber financeiro e o professor/educador. As entrevistas foram realizadas por áudio e registros fotográficos; o foco foi a ação didática em si, preservando, sobretudo, o anonimato de cada criança, diante da ocultação de sua identidade, não comprometendo a ética entre o pesquisador e os participantes da pesquisa.

Neste artigo, é destacada uma atividade da pesquisa em educação financeira e consumo consciente no ensino fundamental, em que é apresentada para as turmas do $1^{\circ}$ segmento do ensino fundamental com foco no $4^{\circ}$ ano. Buscou-se, pelas atividades propostas, incentivar os alunos a refletir sobre consumo mais consciente e mudanças de atitude em relação ao meio em que vivem. A partir dos dados coletados na pesquisa, foi realizada uma análise desses resultados.

Nos trabalhos de Cerbasi (2012), nota-se que há uma perspectiva lúdica de educação financeira e cuidados com o planeta e, diante disso, adaptou-se algumas ideias, construindo cinco atividades, visando um processo de ensino e de aprendizagem 
mais eficiente no que diz respeito a questões financeiras. No entanto, para o presente artigo, é considerada apenas a análise prévia de uma delas para efeitos de discussão e, assim, apontar as reflexões realizadas com os alunos sobre poupança, trabalho e economia. A pesquisa abordou ainda, atividades de listas de compras, feira de troca de mercadorias, reflexões sobre coisas fundamentais e supérfluas e sobre dinheiro e felicidade, planejamento de mesadas, simulação de pesquisa de preços para compra de determinado item, estratégias de geração de rendas, perigos de parcelamentos e endividamentos.

Utilizou-se aqui, segundo a Teoria das Situações Didáticas, uma atividade com o objetivo de identificar coisas que têm preço e coisas que não têm preço, mas têm valor, estimulando a diferença entre dinheiro e felicidade. Nesse sentido, iniciamos a tarefa propondo uma discussão com os alunos, levantando a questão: "Para que serve o dinheiro?'. Propomos aos alunos que listassem coisas que trouxessem felicidade. Foram registradas na lousa as respostas como amor, saúde, amizade, carinho da mãe, carinho do pai, da avó, brincar na rua, pique pega, pique esconde, ir ao shopping, ao cinema, jogar bola, parquinho, piscina, praia. Os alunos destacaram, dentre as opções, as que custam dinheiro e as que não custam nada; falaram que felicidade não custa dinheiro e que muitas pessoas pobres são mais felizes do que as ricas. Então foi feita uma votação do que trazia para o aluno, com destaque para "mais felicidade", quando cada aluno escolheu um item, dentre os listados pela turma. Como resultado da votação, tivemos os mais votados: carinho de mãe, pai e avó (11 votos), amor (5 votos), amizade (5 votos), coisas que não custam dinheiro. Dentre as opções que custam dinheiro, somente ida ao shopping teve um voto.

Durante a tarefa, os alunos refletiram que o valor dos itens não necessariamente significa que eles são valiosos. Coisas sem grande valor financeiro podem ser mais valiosas do que outras coisas caras. Também comentaram que preferiam brincar com os amigos na rua do que ir ao parque ou shopping sozinhos. Tais conceitos são importantes na construção de valores como ética, respeito, cidadania, sustentabilidade. Segundo Silva (2014, p.19), “existem coisas que jamais poderão ser compradas, pois dependem da subjetividade e da personalidade de cada um inteligência, sabedoria, autoestima, talento pessoal, respeito e amor realmente não têm preço".

Utilizou-se, como proposta de atividade, o recurso das fábulas infantis, por ser uma boa forma das crianças aprenderem conceitos econômicos e financeiros de forma 
divertida. Foi feita uma leitura da fábula "A Cigarra e a Formiga", com objetivo de incentivar os alunos a refletir e discutir sobre trabalho, poupança e economia. Então, propôs-se uma discussão da fábula, alertando que há uma mensagem implícita do trabalho permanente, da necessidade de economizar e do risco de se ficar sem nada, se não existir controle, dedicação e empenho.

Após a leitura da fábula, as crianças falaram que a cigarra errou, por não ter guardado comida e que era muito preguiçosa. As crianças falaram que os ensinamentos da fábula são: devemos ouvir os conselhos dos pais, as crianças devem estudar para arrumar um emprego bom, para ser alguém na vida, e que as crianças não devem só brincar, e sim estudar também. Se não estudar, não conseguirá um emprego bom no futuro. Falaram também que a Formiga economizou a comida para o futuro, e que nós devemos economizar também para o futuro; se gastar tudo que tem com "bobeira", não vai sobrar dinheiro. Falaram que tem gente que gasta dinheiro para se "amostrar", fazendo festas caras etc. Citaram também economizar água para o futuro.

A seguir, com objetivo de solidificar a reflexão, distribuiu-se uma folha de papel, lápis coloridos e canetinhas, para os alunos fazerem uma releitura da fábula, com desenhos ou palavras. Alguns resultados apresentados nessa tarefa revelaram preocupação com o meio ambiente, como o aluno A3 que escreveu: “eu aprendi uma lição que economizar é melhor para viver no Brasil, economizar água é lindo e não economizar é horroroso". O aluno A4 desenhou a cigarra cantando e a formiga trabalhando (Figura 1).

Figura 1- Atividade A Cigarra e a Formiga A4

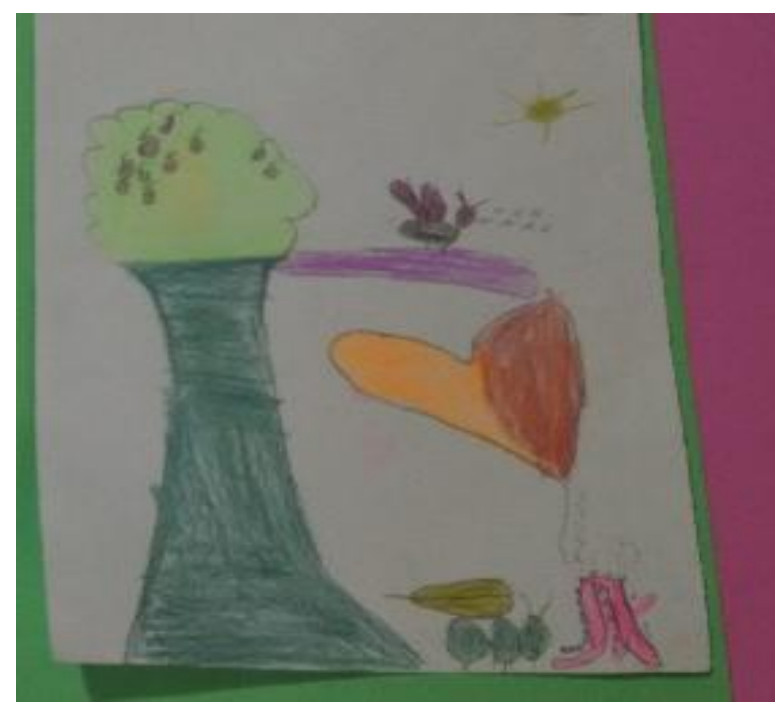

Fonte: dados da pesquisa 
A aluna A5 escreveu que tem que economizar para que possa haver sobra para outro dia, Figura 2.

Figura 2- Atividade A Cigarra e a Formiga A5

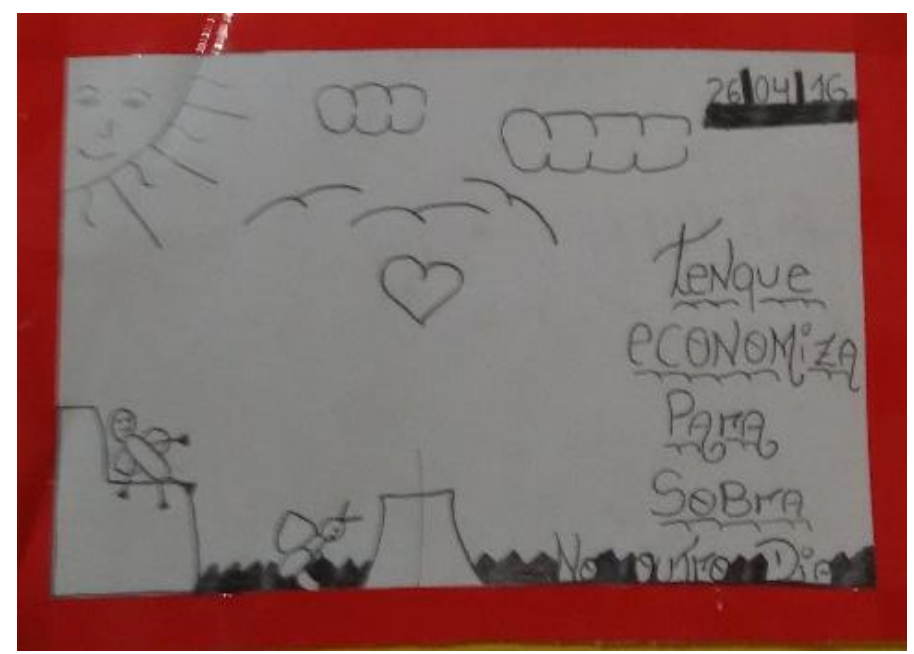

Fonte: dados da pesquisa

A aluna A6 escreveu: "eu achei legal porque ensina a economizar dinheiro e outras coisas". A aluna A7 escreveu: "boa história, devemos dar importância aos conselhos". Como desdobramentos da tarefa, podemos resgatar os valores transmitidos pela fábula, pois "as crianças devem ser expostas a situações onde possam observar atitudes de integridade, solidariedade e respeito pelo outro, de modo a formar valores e desenvolver comportamentos de cidadania" (FERREIRA, 2013, p. 26), pois a formiga acolheu a cigarra, impedindo-a que morresse de frio e fome.

Partindo das ideias de Brousseau (2008, p.9) quando diz que "o professor deverá apresentar progressivamente as situações aos alunos”, vale destacar a proposta do presente trabalho, qual seja buscar estratégias para incentivar os alunos a terem um consumo mais consciente, levando esses conceitos para sua vida. Pretendeu-se, com as tarefas, alcançar os objetivos propostos. As situações apontadas no trabalho envolveram noções didáticas de educação financeira e consumo consciente e, seguindo os pressupostos da teoria indicada, partimos daquilo que o aluno pudesse reconhecer e colocar em prática, no seu dia-a-dia (entorno adidático, quando não há intervenção do professor), de tais saberes. 
Nas atividades trabalhadas, percebemos que os alunos ficaram envolvidos e manifestaram-se naturalmente, por meio do que Brousseau (2008) denomina situação de ação, em que os participantes agiram imediatamente, de forma operacional, utilizando os conhecimentos que já possuíam, mas sem necessariamente explicar os meios que os levaram ao resultado.

Pelas respostas verificadas na primeira atividade, da Cigarra e a Formiga, percebemos que os alunos realizaram as tarefas (situação de ação), produziram um desenho (situação de formulação), debateram as situações, discutiram (situação de validação), estando, aparentemente, aptos a reconhecer e colocar em prática, em seu entorno adidático, tais saberes.

Brousseau (2008, p.18) preocupou-se com "as condições que podem ser propiciadas para que um sujeito qualquer tenha a necessidade de um conhecimento matemático determinado para tomar certas decisões". Dentro do presente projeto, surgiram situações em que os alunos refletiram sobre as melhores estratégias a fim de resolvê-las, como na tarefa da lista de compras, por exemplo.

Compreendemos a dificuldade de todos os alunos da turma atingirem, em período curto de tempo, outra fase essencial do projeto didático: a institucionalização, que é "o fato de o aluno oficialmente levar em conta o objeto de conhecimento e de o professor considerar a aprendizagem do aluno" (BROUSSEAU, 2008). A escolha das condições de ensino justifica-se essencialmente pela necessidade de dar sentido aos conhecimentos. Como a pesquisa pretende "plantar a sementinha em cada criança", essa fase não será verificada de imediato. Nossa intenção é inserir a educação financeira e o consumo consciente, trabalhando-os nas séries iniciais, estimulando a consciência crítica dos alunos para terem autonomia ao lidar com seus recursos financeiros no futuro.

Cerbasi (2004) defende que na educação financeira das crianças, há que se estabelecer regras desde cedo, ensinando às crianças, por exemplo, "nas idas ao shopping, que presentes são ganhos em datas festivas" ou que "estamos abrindo mão de coisas que gostaríamos de ter agora, para tê-las no próximo ano, sem atrapalhar nossas contas" (CERBASI, 2004, p.89). Alerta também para o exemplo que os pais devem dar aos filhos, pois "não adianta pedir para economizar energia elétrica e deixar as luzes acesas na casa inteira" (CERBASI, 2004, p.91).

Uma lição financeira fundamental é a de que existe um custo de oportunidade do dinheiro (CERBASI, 2004); a partir de práticas cotidianas e de simulações do dia-a- 
dia dos adultos, as crianças vão aprendendo noções básicas de educação financeira e de consumo consciente. Pode-se incentivar os jogos que envolvam decisões de compra e acúmulo de riquezas, como, por exemplo, o jogo Banco Imobiliário. Outro passo importante na educação financeira seria "dar permissão os filhos para imitar os adultos em situações de escolha e compra com recursos limitados". (CERBASI, 2004, p.93), como planejamento das próximas férias ou de uma festa de aniversário.

Os pais devem também estimular a responsabilidade pessoal, como na hipótese de se propor uma mesada aos filhos, "eles aprenderão bastante quando perceberem que seus recursos são escassos". Quando os filhos se tornarem adolescentes, podem participar nas decisões sobre o orçamento doméstico da família e, assim, nas palavras de Cerbasi (2004, p.93), “o acompanhamento dos custos da casa e monitoramento da poupança para atingir certos objetivos proporcionam excelente aprendizado sobre finanças para os filhos".

\section{CONSIDERAÇÕES FINAIS}

Percebemos, durante a realização das atividades na turma, que os alunos ficaram muito empolgados e participativos. Questionaram, buscaram estratégias para resolver as questões, defenderam seus argumentos, associaram trabalho com dinheiro e refletiram sobre os temas propostos, como no caso da participação no orçamento doméstico, nas listas de compras, no empreendedorismo infantil ou mesmo vinculando a atividade escolar com a prática social. Diante da intenção de disponibilizar ao aluno os saberes matemáticos, pleiteia-se que ele consiga utilizá-lo fora do contexto de ensino, mesmo sem nenhuma indicação intencional.

É importante que os pais e professores aproveitem as situações do cotidiano para educarem financeiramente as crianças de todas as idades, com viés nas economias do meio ambiente, fazendo-as interagir nas decisões de consumo, por exemplo. Tais situações são muito ricas de ensinamentos e motivadoras para as crianças, sendo um equívoco os pais acharem que os filhos não têm condições de entender, além de tentar protegê-los, pois o mercado e a mídia possuem outras prioridades, isto é, de interesses que estão aquém, ou mesmo na direção oposta ao proposto pela educação financeira.

O Brasil é, predominantemente, um país onde as pessoas chegam à velhice com dificuldades financeiras, dependentes da previdência e da saúde pública, com possível queda do padrão de vida e, muitas vezes, dependentes dos familiares para pagar 
tratamentos de saúde. Por que, então, não discutir educação financeira nas escolas? Vale ressaltar que, além de importante para a criação de hábitos saudáveis de consumo, ajuda no planejamento de gastos, forma adultos conscientes, contribui para a diminuição dos índices de inadimplência, trabalha noções de planejamento financeiro, economia, orçamento doméstico, poupança, aposentadoria e consumo consciente.

Em momentos de crise econômica em todas as partes do mundo, educar financeiramente a população pode ser uma mobilização de ações de modo a causar menos impactos negativos na sociedade, evitando assim, perpetuar a triste realidade (desemprego, dívidas etc.) em que se encontra. A educação financeira surge como um mecanismo de apoio e iniciação para que, quando adultos, os estudantes da Educação Básica saibam lidar bem com o dinheiro. Desempenhando um papel expressivo na formação da cidadania, proporciona aos estudantes uma maior consciência em relação ao consumo, aguçando o senso crítico em relação às oportunidades que as relações de consumo oferecem. "Ser um cidadão crítico é saber avaliar as oportunidades de consumo, formar sua própria opinião e expor suas ideias, não sendo influenciado pela opinião de outras pessoas, pela mídia ou pelas propagandas apelativas" (OLIVEIRA; STEIN, 2013, p.7).

Apesar de a pesquisa ter se originado e desenvolvido em um ambiente sócioeconômico desfavorecido, de escola pública, salientamos que as atividades e indagações são amplamente utilizadas para crianças de todos os níveis econômicos, podendo ajudar no crescimento dos mais humildes aos mais abastados.

Existem outras potencialidades que não foram abordadas nesse trabalho. Mas, vale destacar a importância de cada uma delas para o surgimento de novas pesquisas envolvendo o tema, pois ainda há muito o que discutir, assim esperamos que novas pesquisas possam ampliar e aprofundar tais discussões.

Discutir educação financeira em casa e nas escolas é um bom começo e, por isso, esta investigação vem somar os esforços de pequenos grupos de pesquisa que estão, atualmente, ensejados em divulgar as pesquisas com este tema como, por exemplo, os grupos de pesquisa certificados pelas universidades, com base no CNPq e, em particular, no grupo de pesquisa Investigações no Ensino de Matemática e Ciências, da qual faz parte este trabalho. 


\section{REFERÊNCIAS}

ARTIGUE, M. L'ingenierie didactique: un instrument privilegie pour une prise en compte de la complexité de la classe. $11^{\circ}$ International Conference on the Psychology of Mathematics Education. Anais... BERGERON, J. C. Montreal, Canada. I-III: 19-25 p. 1987.

ARAÚJO, R. M. B. Alfabetização Escolar: compromisso social na educação das crianças. (Dissertação de Mestrado). Universidade Metodista de São Paulo. São Bernardo do Campo-SP, 2009.

BROUSSEAU, G. Introdução ao estudo das Situações Didáticas: Conteúdos e Métodos de Ensino. Trad. de Camila Bogéa. São Paulo: Ática, 2008.

CAMPOS, M. B. Educação Financeira na matemática do Ensino Fundamental: Uma análise de produção de significados. Dissertação (Mestrado Profissional em Educação Matemática). Universidade Federal de Juiz de Fora, Juiz de Fora (MG), 2012.

CERBASI, G. Casais inteligentes enriquecem juntos. São Paulo: Gente, 2004.

CERBASI, G.; SOUSA, M. Descobrindo o valor das coisas: o guia da educação financeira para pais e professores ensinarem seus filhos brincando. 1 ed. São Paulo: Gente, 2012.

FERREIRA, R. Educação financeira das Crianças e Adolescentes. 1 ed. Lisboa: Escolar, 2013.

KISTEMANN, M. A.; LINS, R. C. Enquanto isso na Sociedade de Consumo LíquidoModerna: a produção de significados e a tomada de decisão de indivíduos consumidores. Bolema, v.28, n.50. São Paulo, 2014.

KIYOSAKI, R. T. Pai rico, pai pobre: o que os ricos ensinam a seus filhos sobre dinheiro. Trad. Maria José Cyhlar Monteiro. Rio de Janeiro: Elsevier, 2000.

NISKIER, A. Sustentabilidade e Educação. 1 ed.. São Paulo: SESI-SP, 2012.

OLIVEIRA, S.S; STEIN, N.R. A Educação Financeira na Educação Básica: um novo desafio na formação de professores. Taquara, RS: Universo Acadêmico, v. 8, n. 1, jan./dez.2015.

ROMEIRO, A. R. Desenvolvimento sustentável: uma perspectiva econômicoecológica. Estudos Avançados. v. 26, n. 74, p. 65-92, 2012.

SILVA, A. B. B. Mentes Consumistas. 1. ed. São Paulo: Globo, 2014. 